\title{
Avaliação da aprendizagem em tempos de progressão continuada: o que mudou? Um estudo de teses e dissertações sobre o tema (2000-2010)
}

Márcia Aparecida Jacomini*

\section{Resumo}

Neste artigo são analisadas 22 teses e dissertações produzidas no período de 2000 a 2010 sobre avaliação escolar no regime de progressão continuada. É um trabalho de revisão de produção acadêmica, com leitura completa dos textos e coleta das seguintes informações: referência bibliográfica, estrutura do trabalho, procedimentos metodológicos, objetivos, referencial teórico, conclusões, qualidade do resumo e contribuições para o debate. Verificouse que os trabalhos fizeram pouca referência às pesquisas correlatas e quase não trouxeram novas contribuições. Concluiu-se que futuros trabalhos sobre essa temática devem avançar em aspectos pouco desenvolvidos nas pesquisas analisadas como o estabelecimento de relações entre os dados da pesquisa empírica e o contexto mais amplo da educação brasileira e o aprofundamento da análise e interpretação dos dados. Para isso, as pesquisas de revisão da produção acadêmica podem trazer contribuições importantes.

Palavras-chave: Revisão de produção acadêmica. Avaliação. Progressão continuada.

\section{Introdução}

Embora discussões sobre progressão continuada datem da década de 1920, foi principalmente nos anos de 1990, em especial após a promulgação da Lei de Diretrizes e Bases da Educação Nacional, Lei n. 9.394 (BRASIL, 1996), que muitas redes de ensino, notadamente redes municipais, organizaram o ensino em ciclos com progressão continuada entre os anos letivos de cada ciclo. Em alguns casos, a exemplo do que aconteceu na rede estadual paulista, a reorganização

* Doutora em Educação, Faculdade de Educação da Universidade de São Paulo, USP. Professora do Departamento de Educação da Escola de Filosofia, Letras e Ciências Humanas da Universidade Federal de São Paulo, Unifesp. E-mail: marciajacomini@uol.com.br 
representou tão somente o agrupamento das séries em dois "blocos" com a adoção da progressão continuada no decorrer dos anos e o estabelecimento de reprovação por desempenho somente no último ano de cada "ciclo". Houve na prática a manutenção de uma organização seriada com progressão continuada.

Neste texto, serão apresentados dados de uma pesquisa que analisou teses e dissertações, no período de 2000 a 2010, sobre avaliação escolar no contexto da implantação da progressão continuada em diferentes redes de ensino. Trata-se de um trabalho de revisão da produção acadêmica sobre progressão continuada, com um recorte para as pesquisas que se dedicaram à avaliação escolar.

Os trabalhos de revisão sistemática da produção acadêmica sobre organização do ensino em ciclos e progressão continuada podem contribuir tanto para subsidiar a elaboração e implementação dessas políticas (MAINARDES, 2009) quanto para sistematizar o conhecimento sobre o tema e indicar lacunas e aspectos que exigem maior aprofundamento.

Nessa perspectiva, estão os trabalhos de Mainardes (2006, 2007a, 2009) que tratam da produção acadêmica sobre ciclos, o trabalho de Sousa e Barreto (2004) que analisou a produção sobre ciclos e progressão continuada no período de 1990 a 2002, e o de Contiero (2009) sobre progressão continuada, no período de 2000 a 2007.

Este estudo não deve ser considerado uma revisão sistemática de pesquisas no sentido atribuído por Philip Davies (2007) e David Gough (2007), pois nem todas as etapas foram seguidas de forma rigorosa, entretanto parte do protocolo foi seguido, qualificando-a no rol das revisões ou sínteses sistemáticas de pesquisas acadêmicas.

Os trabalhos analisados neste artigo foram selecionados a partir do levantamento de teses e dissertações sobre progressão continuada, 2000-2010, realizado pelo Grupo de Pesquisa Políticas Educacionais e Práticas Educativas - GPPEPE do Programa de Pós-Graduação em Educação da Universidade Estadual de Ponta Grossa - PR (STREMEL; MAINARDES, 2011).

Os dados bibliográficos, o resumo e as palavras-chave foram coletados por Silvana Stremel e Jefferson Mainardes (2011) nos seguintes sítios: Banco de Teses da 
Capes, Domínio Público - Biblioteca Digital, Biblioteca Digital Brasileira de Teses e Dissertações e nos sites das bibliotecas da Universidade de São Paulo, da Universidade Estadual de Campinas, da Pontifícia Universidade Católica de São Paulo, da Universidade Estadual Paulista Júlio de Mesquita Filho, da Universidade Católica de Santos. Para localização dos trabalhos foram usados os seguintes descritores: regime de progressão continuada, progressão continuada, ciclos ${ }^{1}$.

O levantamento envolve teses e dissertações sobre organização do ensino em ciclos e progressão continuada, classificadas em: 1) levantamento de teses e dissertações sobre a organização da escolaridade em ciclos no Brasil, 2000 a 2011, 2) levantamento de teses e dissertações sobre progressão continuada, 2000 a 2010.

Sobre ciclos foram coletados 217 trabalhos e classificados em 17 categorias por Stremel e Mainardes (2011).

Em relação à progressão continuada, foram coletados 93 trabalhos, sendo 74 dissertações e 19 teses. Estes trabalhos foram classificados em 9 categorias pela autora deste texto, sendo 22 ( 3 teses e 19 dissertações) sobre a temática da avaliação no regime de progressão continuada. $\mathrm{O}$ texto completo das teses e dissertações foram obtidos nas bibliotecas das instituições ou por meio de contato com os autores.

Para a análise dos trabalhos, procedeu-se a leitura completa dos textos e o preenchimento de uma ficha que permitiu capturar as seguintes informações: referência bibliográfica, estrutura do trabalho (número de páginas e capítulos), procedimentos metodológicos, objetivos, referencial teórico, conclusões, qualidade do resumo e contribuições para o debate sobre o tema.

Este texto está dividido em três partes. Na primeira discute-se, brevemente, a progressão continuada e a avaliação escolar no contexto da experiência brasileira. $\mathrm{Na}$ segunda, são apresentados os dados e uma análise das características dos trabalhos selecionados. Em seguida, procede-se à análise das mudanças na concepção e na prática da avaliação escolar presentes nas teses e dissertações, e as principais contribuições para o debate. Nas considerações finais são expostos lacunas e aspectos que demandam maior aprofundamento nos estudos sobre a avaliação escolar no contexto da progressão continuada.

1 É importante destacar que não se trata de um levantamento completo, posto que ele não foi realizado junto a todos os programas de pós-graduação em educação ou áreas afins, e que nem todos os trabalhos sobre o tema estão disponíveis nos bancos utilizados. 


\section{Progressão continuada e avaliação escolar}

As primeiras discussões sobre progressão continuada, ou aprovação automática, como foi chamada na época, ocorreram no Brasil na década de 1920, quando Sampaio Dória propôs que não houvesse reprovação na passagem da primeira para a segunda série do Ensino Primário na rede estadual paulista. Naquele momento, o principal propósito do então diretor da Instrução Pública do Estado de São Paulo era evitar que metade das vagas da primeira série fosse ocupada pelos alunos repetentes, num contexto de não atendimento da demanda escolar pela rede pública de ensino (AZANHA, 1987).

Desprovida de qualquer discussão sobre forma de organização do ensino e dos malefícios da reprovação para a criança e o sistema de ensino, o principal argumento recaiu sobre a necessidade de o Estado garantir vaga ao maior número possível de crianças, tratava-se de uma discussão sobre ampliação do acesso à escola num momento histórico em que a matrícula no período de escolarização obrigatória correspondia a $3,4 \%$ da população ${ }^{2}$.

A proposta de Sampaio Dória recebeu duras críticas e não prosperou. A escola primária paulista manteve os altos índices de reprovação até meados da segunda metade do século XX, quando políticas de contenção da reprovação escolar foram implementadas (AZANHA,1987; BARRETO, MITRULIS, 1999; JACOMINI, 2002; MAINARDES, 2007b).

A discussão sobre reprovação anual e progressão continuada voltou ao cenário educacional brasileiro na década de 1960, protagonizada por Dante Moreira Leite e Almeida Júnior. Estes educadores qualificaram o debate analisando a reprovação do ponto de vista pedagógico e educacional. Argumentaram que a reprovação encerra contradição ao processo educativo e implica na não garantia do direito à educação, na medida em que corrobora a evasão. Cientes das resistências dos educadores e da sociedade à ideia que pregavam do fim da reprovação, propuseram um amplo debate com os professores no sentido de, por meio de argumentos, convencê-los da importância de tal medida. Esse convencimento era de fundamental importância, pois seriam eles que

2 Dados organizados por Mansano Filho, Oliveira e Camargo (1999). Em 1996, o percentual da população matriculada no período de escolarização obrigatória era de $21,1 \%$, com destaque para o fato de que em 1920 a educação obrigatória abrangia os quatro primeiros anos do ensino primário, em 1996 os oito anos do Ensino Fundamental. 
implementariam uma ruptura com a forma tradicional de lidar com as diferenças no processo de escolarização.

O modelo de escola predominante em nossa sociedade é a chamada escola graduada, organizada em séries que correspondem a um ano letivo. Nela, normalmente, o conteúdo é fragmentado em períodos estanques e segue a lógica do menos para o mais complexo, o tempo, os métodos de ensino e a avaliação são padronizados para uniformizar a aprendizagem. Os altos índices de reprovação que grassam em nossas escolas desde a origem do processo de escolarização começaram a ser questionados, de forma mais sistemática e ampla, somente na segunda metade do século XX. Formas alternativas de organizar o ensino e a não utilização da reprovação como procedimento pedagógico, contribuíram para esse debate.

As experiências de ensino não seriado nas décadas de 1960, 1970 e 1980 baseadas, do ponto de vista legal, na Lei $n^{0} 5.692$ (BRASIL, 1971), que admitia em caráter experimental outras formas de organização do ensino, contribuíram para a ampliação do debate sobre seriação e reprovação anual, colocando em cena teses contrárias ou a favor das políticas de não reprovação anual (ARELARO, 1988; BARRETO, MITRULIS, 1999).

Nem sempre essas experiências foram avaliadas de forma criteriosa, tendo em conta as implicações dos condicionantes internos e externos à escola para a operacionalização de mudanças que envolviam rupturas com concepções de educação escolar bastante consolidadas nas práticas escolares. Dessa forma, algumas vezes elas foram compreendidas, principalmente pelos professores da Educação Básica, como mal sucedidas. Assim, quando em 1996 a nova Lei de Diretrizes e Bases da Educação Nacional explicitou, em seu Art. 23, a seriação como uma entre outras formas de organização do ensino, retirando, portanto, a centralidade que possuía nas leis anteriores, ainda era hegemônica a concepção de ensino seriado e de reprovação anual entre os educadores.

Contudo, as ideias e propostas de rever essa forma tradicional de organização do ensino foram reforçadas pela legislação e ganharam maior visibilidade no cenário educacional, protagonizadas por experiências municipais e estaduais de organização do ensino em ciclos com progressão continuada e de progressão continuada. Se por um lado essas experiências trouxeram em comum a perspectiva de, no caso dos ciclos, romper com a seriação e, no caso da 
progressão continuada, com a reprovação anual, por outro, a forma como elas foram concebidas e implementadas guarda significativas diferenças.

Experiências como a Escola Plural de Belo Horizonte (BELO HORIZONTE, 1994), a Escola Cidadã de Porto Alegre (PORTO ALEGRE [1996], AZEVEDO, 2000), a Organização do Ensino Fundamental em três Ciclos na rede municipal de São Paulo em 1992 (SÃO PAULO, 1992; JACOMINI, 2002), a implantação dos Ciclos de Aprendizagem na rede municipal de Curitiba em 1999 (KNOBLAUCH, 2004), a Escola Ciclada na rede estadual de Mato Grosso a partir de 1996 (CABRERA, 2006; CAMPOS, 2008) são alguns exemplos de organização do ensino em ciclos com progressão continuada entre os anos que compõem cada ciclo.

Em meio às diversas experiências de ciclos e progressão continuada, há aquelas em que se manteve uma concepção e uma prática de seriação com progressão continuada entre os anos do chamado ciclo, como é o caso da rede estadual paulista.

Nesse contexto,éimportante esclarecer a diferença entre ciclos e progressão continuada, posto que muitas vezes são tidas como sinônimos. Os ciclos dizem respeito à forma de organizar o ensino e se contrapõem à seriação, enquanto a progressão continuada se refere à decisão sobre promoção e reprovação dos alunos; ou seja, em que momento do processo educativo os alunos podem ser reprovados por baixo desempenho escolar, ela se contrapõe à reprovação anual na medida em que propõe a progressão do aluno durante um período superior ao de um ano letivo (JACOMINI, 2010).

Luiz Carlos de Freitas (2003a; 2003b) afirma que as concepções de organização do ensino em ciclos estão mais vinculadas às propostas educacionais progressistas e transformadoras, enquanto a progressão continuada se vincula a concepções mais conservadoras e liberais. Essa afirmação se justifica na medida em que a adoção da progressão continuada desprovida de mudanças na organização curricular, no tempo e espaço escolares e na avaliação concorre, muitas vezes, para uma progressão do estudante desprovida de aprendizagem, produzindo os chamados excluídos do interior. Entretanto, é importante destacar que a progressão continuada implementada juntamente com os ciclos concorre para a construção de uma nova forma de conceber o processo educativo e para a superação dos altos índices de reprovação, trata-se de uma perspectiva de superação da reprovação como mecanismo de seleção dos alunos na Educação Básica, o que a coloca como progressista num contexto em que a reprovação escolar é naturalizada. 
A seleção das teses e dissertações para este trabalho considerou a classificação de progressão continuada dada pelos autores às experiências que eles estudaram. Porém, mesmo anunciando, no título e no resumo, que se tratava de uma pesquisa sobre a avaliação no regime de progressão continuada, muitas vezes eles também se referiram às experiências analisadas como ciclos, o que corrobora a confusão acerca dessa temática. Isso ocorre, também, porque normalmente a legislação faz referência à organização do ensino em ciclos, mesmo não contemplando concepções e medidas práticas que justifiquem que determinadas experiências sejam assim denominadas.

A avaliação da aprendizagem escolar está diretamente vinculada às discussões sobre ciclos e progressão continuada. Há uma compreensão entre estudiosos do tema que a avaliação possui centralidade nas propostas de ciclos e de progressão continuada. "Certamente, dentre todas as práticas e rotinas escolares, aquela que mais diretamente é 'abalada' com a implantação dos ciclos é a avaliação, sendo sua re-significação na prática escolar necessária, para tornar realidade a reorganização do processo educativo". (SOUSA; BARRETO, 2004).

De acordo com Barreto et al. (2001), com base numa pesquisa que analisou artigos publicados em periódicos acadêmicos sobre a avaliação na Educação Básica nos anos de 1990, os estudos sobre avaliação podem ser classificados em quatro categorias: referências e modelos; avaliação na escola e da escola, avaliação de sistema e avaliação de políticas educacionais (BARRETO et al., 2001).

Considerando essa classificação, compreende-se que os trabalhos analisados neste texto dizem respeito à avaliação na escola que, de acordo com as autoras, entre outros aspectos, diz respeito à avaliação da aprendizagem e às práticas avaliativas. Assim, tratar-se-á da avaliação escolar, ou melhor, de concepções e de práticas de avaliação dos estudantes.

Os anos de 1980 marcaram o início de mudanças importantes na concepção de avaliação escolar. Naquele momento, entre outros autores, Luckesi (2000) chamou a atenção para o caráter da avaliação escolar, pontuando que comumente o que se praticava na escola era verificação da aprendizagem, com propósitos de promoção e reprovação e não propriamente avaliação, o que implica numa análise criteriosa das informações coletadas com vistas à organização didáticopedagógica mais adequada à garantia de aprendizagem a todos os alunos. 
Vários autores debruçaram-se na análise sobre como se dá os processos avaliativos na escola, buscando mostrar como tais práticas não contribuem para a aprendizagem e a formação dos estudantes e como, por vezes, acabam reforçando a exclusão. Também se dedicaram a apresentar outras concepções de avaliação que vêm sendo incorporadas em maior ou menor grau às práticas educativas (PERRENOUD, 1999; ESTEBAN, 2002; PARO, 2001).

Ao analisar os trabalhos que trataram da avaliação no regime de progressão continuada buscou-se verificar, entre outros aspectos, em que medida os professores da Educação Básica mudaram suas concepções e práticas sobre a avaliação.

\section{Produção acadêmica sobre a avaliação da aprendizagem no regime de progressão continuada (2000-2010)}

Os trabalhos analisados foram desenvolvidos e defendidos em 12 instituições de Ensino Superior localizadas no estado de São Paulo, assim distribuídos: quatro na Faculdade de Educação da Universidade de São Paulo (FEUSP), cinco na Pontifícia Universidade Católica de São Paulo (PUC-SP), três na Universidade Estadual Paulista Júlio de Mesquita Filho/Araraquara (UNESPAraraquara), e dois na Universidade Metodista de São Paulo, um em cada uma das demais instituições: Universidade Estadual Paulista Júlio de Mesquita Filho/Marília, Universidade do Oeste Paulista, Universidade Presbiteriana Mackenzie, Universidade Federal de São Carlos, Universidade de São Paulo Ribeirão Preto, Centro Universitário Moura Lacerda, Universidade Estadual de Campinas, Universidade Metodista de Piracicaba.

Há concentração de trabalhos nos anos de 2002, 2004, 2005 e 2007, sendo este último, o ano com maior produção: seis dissertações. As teses foram defendidas nos anos de 2004, 2005 e 2009, sendo duas na FEUSP e uma na PUC-SP. Não foi encontrado nenhum trabalho nos anos de 2000, 2008 e 2010.

Das 22 pesquisas analisadas, 19 são sobre a rede estadual de ensino do estado São Paulo, uma sobre rede estadual de ensino do Rio de Janeiro, uma sobre a rede municipal de ensino de São José dos Campos - SP, e uma sobre a rede municipal 
de ensino de Araçatuba - SP. A maioria das pesquisas foi realizada em escolas (15), três estudos foram realizados junto a Diretorias Regionais de Ensino da Secretaria de Estado da Educação de São Paulo, uma na rede municipal de ensino de São José dos Campos, uma na rede municipal de ensino de Araçatuba, uma em oito escolas da rede estadual de ensino do Rio de Janeiro e uma com alunos do curso de complementação pedagógica da faculdade onde a pesquisadora lecionava.

É interessante observar que, mesmo fazendo o levantamento em sítios que contemplam trabalhos dos programas de pós-graduação de todas as regiões do país, as pesquisas encontradas foram todas realizadas em universidades do Estado de São Paulo. O fato de a maioria dos trabalhos ter sido realizado sobre a rede estadual paulista revela que os autores compreendem que a questão principal da Deliberação do Conselho Estadual de Educação n. 9/1997 (SÃO PAULO, 1997) é o regime de progressão continuada e não a organização do ensino em um ou mais ciclos, conforme previsto no parágrafo primeiro do Art. $1^{\mathrm{o}}$ da Deliberação. Entende-se que a implantação da progressão continuada em 1998 não foi acompanhada por uma organização do ensino em ciclos, tal como ocorreu em outras redes, principalmente municipais.

Há um conjunto de trabalhos que investigaram a avaliação em redes que adotaram a progressão continuada, mas que também organizaram o ensino em ciclos e que, portanto, não fizeram parte das teses e dissertações aqui analisadas. Junta-se a isso o fato de ser a maior rede de ensino do país, com 4.604.046 alunos em 2011, de acordo com o Censo Escolar ${ }^{3}$, o que lhe dá grande visibilidade no cenário nacional.

Os objetivos apresentados nos trabalhos foram classificados em categorias temáticas (BARDIN, 2004), constituindo quatro grupos: 1) análise das práticas de avaliação em redes de ensino que implementaram progressão continuada (14 pesquisas); 2) análise das características e tendências que a avaliação escolar adquiriu com a implantação da progressão continuada (5 pesquisas); 3) interpretação das concepções e representações dos professores acerca da avaliação escolar (2 pesquisas); 4) análise da atuação de uma Secretaria Municipal de Educação na preparação de professores, diretores e coordenadores para a implementação da progressão continuada e de uma nova concepção de avaliação (1 pesquisa).

3 Fonte: MEC/Inep/Deed. 
A análise dos objetivos apresentados nas teses e dissertações indica que a maior parte dos pesquisadores estava interessada em saber se a avaliação escolar havia mudado com a implementação da progressão continuada, posto que as legislações referentes à progressão continuada apresentam outra forma de conceber os processos avaliativos.

Em relação ao método de pesquisa, os autores classificaram seus estudos como pesquisa qualitativa em educação, conforme pode ser observado no Quadro 1.

Quadro 1 - Metodologia de Pesquisa ${ }^{4}$

\begin{tabular}{|l|l|}
\hline Metodologia de Pesquisa & Quantidade \\
\hline Pesquisa qualitativa em educação & 18 \\
\hline Pesquisa qualitativa em educação - estudo de caso & 2 \\
\hline Pesquisa qualitativa em educação - estudo etnográfico & 1 \\
\hline Pesquisa documental & 1 \\
\hline Total & 22 \\
\hline
\end{tabular}

Fonte: Os autores (2014).

Os procedimentos de coletas de dados mais frequentes foram: questionários e entrevistas com professores, diretores e coordenadores, observação do cotidiano escolar, de aulas e do Horário de Trabalho Pedagógico Coletivo (HTPC), análise dos registros da escola, análise documental. Apenas dois pesquisadores fizeram entrevistas com alunos, e nenhum com pais. Os autores mais citados na apresentação da metodologia foram Bogdan, Biklen $(1982,1991,1994)$ e Lüdke e André (1986), embora, incluindo esses dois, 26 autores tenham sido citados. Em sete dissertações, não havia nenhuma referência a autores na apresentação dos procedimentos metodológicos da pesquisa.

Como parte da contextualização dos estudos, buscou-se verificar em que medida as pesquisas realizaram abordagem macro, ou seja, se analisaram ou fizeram referência aos condicionantes mais amplos da progressão continuada e da avaliação escolar, e foram encontrados apenas três trabalhos que fizeram isso: uma tese e duas dissertações. De modo geral, os estudos se restringiram à apresentação de algumas concepções de avaliação, tendo como base autores

4 Para compor este quadro seguiu-se a denominação dos autores em relação aos seus trabalhos. 
nacionais e estrangeiros, e à apresentação e análise dos dados empíricos. Poucos trabalhos avançaram para uma interpretação dos dados relacionando-os ao contexto educacional mais amplo.

Todos os trabalhos trataram da avaliação escolar ou avaliação da aprendizagem, seja em forma de revisão da literatura, assim denominado pelos autores, ou como apresentação das ideias de alguns teóricos que tratam do tema. Procedeu-se a um levantamento dos autores citados no capítulo das teses e dissertações relativo à avaliação escolar e verificou-se que foram citados 157 autores. Contudo, é importante destacar que nem todos os autores citados são estudiosos da área de avaliação escolar, em alguns casos a citação estava relacionada ao fato do autor ter feito referência à avaliação ao tratar da organização do ensino em ciclos ou da progressão continuada.

Como forma de caracterizar as principais referências teóricas sobre avaliação utilizadas nas teses e dissertações foi computado em quantos trabalhos cada autor foi citado. Do total de autores, 112 foram citados uma única vez, 32 foram citados entre dois e quatro trabalhos, 13 foram citados em 5 ou mais trabalhos. Enquadram-se nesse último caso os seguintes autores: Phillippe Perrenoud (17), Zilma de Moraes Ramos de Oliveira (5), Almeirindo Janela Afonso (5), Heraldo Marelim Vianna (6), Charles Hadji (16), Cipriano Carlos Luckesi (17), Ana Maria Saul (8), Sandra Maria Zákia L. Sousa (10), Jussara Hoffmann (9), Pedro Demo (7), Menga Lüdke e Zélia Mediano (5), Mere Abramowicz (9), Maria Tereza Esteban (7), Celso dos Santos Vasconcellos (5). Observa-se que entre os três autores mais citados, dois são franceses (Phillippe Perrenoud e Charles Hadji) e um brasileiro (Cipriano Carlos Luckesi).

Considera-se que o pensamento desses autores constitui a base teórica sobre a qual os trabalhos analisados neste estudo foram desenvolvidos.

As principais ideias sobre avaliação escolar apresentadas nas teses e dissertações, tendo como referência os 13 autores mais citados são: a) a constatação, a partir da década de 1980, de que avaliação funciona como um mecanismo de exclusão escolar; b) a crítica a uma prática avaliativa calcada na ideia de classificação e seleção dos alunos e instrumento de decisão sobre promoção e retenção; c) a compreensão da avaliação como instrumento essencial para o desenvolvimento do processo de ensino e de aprendizagem, servindo como mediadora da açãoreflexão-ação com vistas a melhorar a aprendizagem, na perspectiva da avaliação 
formativa; d) a compreensão de que a avaliação é constitutiva da condição humana, que ela é necessária para corrigir percursos e que na escola ela faz parte do processo educativo, com vistas a acompanhar a aprendizagem e adequar o ensino.

Também foram computados os autores utilizados nas teses e dissertações para discutir a progressão continuada e os ciclos. Nos capítulos ou tópicos das teses e dissertações que trataram da progressão continuada, foram citados 63 autores, embora nem todos estudiosos do tema. Desse total, 59 foram citados em um ou dois trabalhos, nove em três ou quatro trabalhos, e quatro em mais de quatro trabalhos, Jefferson Mainardes (8), Elba Siqueira de Sá Barreto e Eleny Mitrulis (8), Sonia Teresinha de Sousa Penin (9). Observa-se um amplo espectro de autores citados, mas baixa incidência de um mesmo autor na maioria das pesquisas, indicando que os estudos sobre progressão continuada e ciclos ainda não estão vinculados a autores amplamente conhecidos por trabalhos sobre o tema, mesmo os mais citados não o foram na maioria das teses e dissertações.

Além do levantamento dos autores citados para dissertar sobre progressão continuada, verificou-se se as teses e dissertações citaram outras pesquisas sobre ciclos ou progressão continuada, ou seja, em que medida os autores dos trabalhos analisados dialogaram ou consideraram, em seus estudos, pesquisas em nível de mestrado e doutorado que haviam estudado a mesma temática. Constatou-se que duas teses e somente seis dissertações citaram outras pesquisas. Isso sugere que a maioria dos autores das teses e dissertações estudadas não indicou ter feito um levantamento da produção acadêmica sobre o tema, seja para delinear o objeto e estabelecer os objetivos de seu estudo, ou para dialogar com os resultados de pesquisas anteriores. Dessa forma, se verifica uma tendência a repetir-se o mesmo tipo de estudo, com resultados idênticos ou muito parecidos, o que pouco contribui para o avanço do conhecimento sobre o tema.

Ao estabelecerem o objeto e os objetivos dos estudos, de modo geral os autores não o fizeram a partir da observação de tendências apresentadas em estudos anteriores e da verificação de aspectos ainda não estudados, o que exigiria aprofundamento ou abordagem diferenciada, pode-se dizer que cada trabalho estava "reinventando a roda".

O que mudou na avaliação escolar com a progressão continuada?

Como a maioria dos trabalhos buscou verificar, analisar e compreender as 
características e as práticas da avaliação no contexto da progressão continuada, tentou-se apreender, com base nas conclusões dos autores, as mudanças operadas na avaliação escolar após a implementação da progressão continuada nas redes de ensino pesquisadas, com a ressalva de que, por se tratar de pesquisas qualitativas em educação, tais resultados não devem ser generalizados.

Classificaram-se as conclusões dos trabalhos em tela em dois grandes grupos: 1) aqueles que indicaram que houve mudanças nas práticas avaliativas, mas ainda não se pode falar numa prática de avaliação contínua e formativa; 2) aqueles que indicaram mudanças no discurso sobre a avaliação, mas não na prática. Vários trabalhos também indicaram que as escolas não foram preparadas para implementar o regime de progressão continuada, e que nem sempre os professores compreenderam a proposta de avaliação preconizada na legislação que implantou a progressão continuada. Além disso, destacam que as dificuldades de mudar as práticas avaliativas estão vinculadas ao fato de não ter ocorrido mudanças no currículo, no tempo e na estrutura da escola. O Quadro 2 traz as principais conclusões dos trabalhos.

Quadro 2 - Principais conclusões das teses e dissertações acerca da avaliação

\begin{tabular}{|l|l|}
\hline Ocorreram algumas mudanças & Mudou-se o discurso, mas não a prática \\
\hline $\begin{array}{l}\text { A progressão continuada produziu mu- } \\
\text { danças na avaliação, mas ainda não há, nas } \\
\text { escolas, uma prática de avaliação formativa. }\end{array}$ & $\begin{array}{l}\text { Embora os professores, de modo geral, } \\
\text { adotem o discurso oficial sobre o conceito } \\
\text { de avaliação, não significa que houve uma } \\
\text { mudança na prática avaliativa. }\end{array}$ \\
\hline $\begin{array}{l}\text { Existem, nas escolas, práticas avaliativas de } \\
\text { cunho tradicional e práticas que buscam in- } \\
\text { corporar os pressupostos de uma avaliação } \\
\text { formativa e da avaliação contínua. }\end{array}$ & $\begin{array}{l}\text { De modo geral, os professores não com- } \\
\text { preendem a avaliação numa perspectiva } \\
\text { formativa e reiteram seu uso para a tomada } \\
\text { de decisão sobre promoção e reprovação } \\
\text { dos alunos. }\end{array}$ \\
\hline $\begin{array}{l}\text { A avaliação formativa é muitas vezes con- } \\
\text { fundida com a diversificação dos instru- } \\
\text { mentos de avaliação, ou seja, ao aplicar } \\
\text { diferentes formas de avaliar o professor } \\
\begin{array}{l}\text { acredita estar realizando a avaliação for- } \\
\text { mativa. }\end{array}\end{array}$ & $\begin{array}{l}\text { A prática avaliativa dos professores não } \\
\text { incorporou uma visão mais democrática do } \\
\text { processo educativo, conforme estabelece a } \\
\text { legislação sobre progressão continuada. }\end{array}$ \\
\hline \multicolumn{2}{|l|}{$\begin{array}{l}\text { Nem sempre o que os professores dizem } \\
\text { entender por avaliação é o que eles reali- } \\
\text { zam na prática. }\end{array}$} \\
\hline & $\begin{array}{l}\text { A avaliação não mudou com a implantação } \\
\text { da progressão continuada. }\end{array}$ \\
\hline
\end{tabular}

Fonte: Os autores (2014). 
Em estudo sobre revisão da literatura sobre avaliação da aprendizagem e escolas em ciclos, Mainardes e Gomes (2008, p. 243) encontraram conclusões semelhantes a estas nos trabalhos analisados por eles.

Os trabalhos de pesquisa analisados indicaram que as práticas avaliativas efetivamente utilizadas nas escolas geralmente exploram de forma frágil o potencial da avaliação continua e formativa, e que, em muitos casos, a avaliação continua [vem] sendo utilizada com finalidades seletivas e classificatórias (grifos dos autores).

Outra conclusão que merece destaque é a constatação de que o Sistema de Avaliação do Rendimento Escolar do Estado de São Paulo (SARESP) ${ }^{5}$ é o principal orientador da avaliação e das práticas pedagógicas na escola, ou seja, as avaliações são pensadas e organizadas em função do SARESP. Como os resultados das provas são considerados para bonificação dos professores e gestores, as escolas tendem a se organizar em função da preparação dos alunos para a realização das provas. A tendência das avaliações em larga escala delinearem o currículo e as práticas escolares já foi constatada em outros estudos, principalmente quando os resultados são vinculados à remuneração dos professores (RAVITCH, 2010; MOREIRA, 2011; VIDAL; VIEIRA, 2011).

De modo geral, os trabalhos indicam que as propostas de avaliação apresentadas nas redes pesquisadas estão de acordo com os pressupostos da avaliação formativa, considerando as especificidades que ela adquire para os diferentes autores.

O trabalho que estudou a Primeira Avaliação de Ciclos do Estado de São Paulo, concluiu que essa avaliação estava em contradição com os pressupostos da avaliação no regime de progressão continuada na medida em que ela serve à hierarquização e não à regulação da aprendizagem, contrariando os pressupostos da avaliação formativa.

5 As provas que compõem o SARESP são aplicadas a todos os alunos do $3^{\circ}, 5^{\circ}, 7^{\circ}$ e $9^{\circ}$ anos do Ensino Fundamental e do $3^{\circ}$ ano do Ensino Médio. As provas de Língua Portuguesa e Matemática são aplicadas todos os anos e alternadamente são aplicadas provas de Ciências da Natureza (Ciências, Biologia, Química e Física) e Ciências Humanas (Geografia e História). Também são aplicados questionários aos pais, alunos, professores e gestores. De acordo com a Secretaria de Estado da Educação de São Paulo, o SARESP tem como objetivo monitorar as políticas educacionais.

6 Esta avaliação foi realizada em novembro de 2001 com todos os alunos que cursavam as séries finais dos Ciclos I e II, com o objetivo de aferir as condições de continuidade dos estudos no Ciclo seguinte ou no ensino médio. Os alunos com baixo desempenho na prova foram encaminhados para recuperação intensiva no mês de janeiro de 2002. A prova contou com questões de múltipla escolha da disciplina de Língua Portuguesa e produção de texto. (SÃO PAULO, 2001). 
No caso das pesquisas realizadas sobre a rede estadual de ensino de São Paulo, alguns autores reafirmaram que há forte crítica à progressão continuada e defesa do retorno à reprovação anual, por parte dos professores, dos alunos e dos pais.

\section{Contribuições das pesquisas para o debate}

Não se verificou contribuições originais nas pesquisas analisadas. De modo geral, os trabalhos reafirmaram aspectos que outros estudos já haviam apresentado. Entre os aspectos que devem ser considerados na formulação das políticas educacionais, de acordo com as conclusões apresentadas pelos autores dos trabalhos analisados, estão: a necessidade de formação continuada dos professores com vistas a provocar mudanças na forma de ensinar e avaliar; a manutenção das equipes de professores e gestores na escola para a construção de propostas pedagógicas diferenciadas; a centralidade do papel do professor na realização de mudanças na escola; a necessidade de as políticas educacionais serem discutidas com os educadores e a comunidade escolar para sua efetiva implementação; a compreensão de que mudanças nas práticas avaliativas demandam mudanças na escola (currículo, tempo, organização e funcionamento); a importância de considerar os estudos sobre a escola como subsídio à formulação das políticas educacionais.

Também constitui contribuição importante a verificação de que o Saresp tem pautado o currículo, as práticas educativas e a avaliação escolar; ou seja, está influenciando as escolas a realizarem uma adequação pedagógica a serviço das avaliações externas. Como a pesquisa que indicou essas questões foi realizada nas escolas de uma Diretoria Regional de ensino da rede estadual de ensino de São Paulo, cabem estudos quantitativos sobre o tema para verificar em que medida essa é a tendência nas escolas da rede estadual paulista ou se reflete a especificidade das escolas de uma Diretoria Regional de Ensino. Também cabem pesquisas que possam aprofundar o conhecimento e a reflexão sobre a repercussão para a formação dos estudantes do processo educativo ser pautado pelas avaliações externas.

Por último, cabe o registro da constatação de certo descompasso entre o legalmente proclamado e o que de fato é realizado nas escolas. Ao adentrar o cotidiano escolar, os pesquisadores puderam desvelar a multiplicidade de saberes e práticas sobre a avaliação e constatar que, embora concepções de avaliação não tradicionais estejam presentes na escola, sua presença no fazer pedagógico é bastante desigual. 


\section{Considerações finais}

Em relação à produção acadêmica analisada nesta pesquisa, alguns aspectos merecem destaque no que diz respeito à necessidade de maior aprofundamento.

Todos os trabalhos analisados desenvolveram estudos empíricos e, conforme os autores, pesquisas qualitativas em educação, em alguns casos com a especificação de ser estudo de caso ou estudo etnográfico. Todos os trabalhos utilizaram fonte primária de coleta de dados, porém, observou-se grande diversidade na forma de coletar os dados. Chamou a atenção que apenas dois pesquisadores tenham considerado as opiniões dos alunos em seus estudos e a ausência de estudos que considerassem as opiniões dos pais ou responsáveis pelos estudantes.

Uma das características da pesquisa qualitativa é o contato direto e prolongado do pesquisador com o "ambiente natural" que está pesquisando (LÜDKE, ANDRÉ, 1986), no caso de estudos etnográficos faz-se necessário a triangulação dos dados obtidos, ou seja, é importante que o pesquisador tenha grande capacidade de observação e percepção do contexto de seu objeto de pesquisa, de forma a perceber diferentes aspectos da realidade utilizando-se, para isso, de diversos procedimentos metodológicos (STAKE, 1983).

Observaram-se diferenças tanto no uso dos procedimentos quanto no tempo dedicado à coleta de dados. A forma como as pesquisas foram desenvolvidas suscitou questionamento sobre a necessidade de se aprofundar as questões relativas aos procedimentos metodológicos da chamada pesquisa qualitativa em educação. Talvez, sob esse "grande guarda-chuva", esteja pondo-se um conjunto de pesquisas que apresentam grande fragilidade em relação ao método de pesquisa.

Embora os dados coletados em pesquisas qualitativas sejam predominantemente descritivos, espera-se um processo de análise indutiva e interpretações que façam avançar o conhecimento na área. Neste aspecto, há importante limitação nos trabalhos analisados. Nem sempre as descrições foram acompanhadas de análises e interpretações que indicassem novas possibilidades de compreensão dos fenômenos estudados.

Outro aspecto que merece maior precisãoé a revisão da literatura, o que se observou foi a apresentação de alguns autores e ideias sobre determinada temática, e não 
uma revisão de literatura propriamente dita. Mesmo considerando a necessidade de recortes quando se realiza uma revisão da literatura sobre a temática que se está estudando, chamou a atenção o fato de a maioria dos trabalhos não ter feito sequer uma pequena revisão da produção sobre a temática da avaliação na progressão continuada no que diz respeito às teses e dissertações existentes, ou seja, os autores, de modo geral, não buscaram conhecer os trabalhos de seus pares. Talvez, esse seja um dos fatores que explica a repetição das pesquisas analisadas tanto na forma de realizá-las quanto nas conclusões. Essa forma de conduzir as pesquisas pode contribuir para a proliferação de estudos com as mesmas características (não apresenta questões novas), e tende a manter as lacunas, por vezes até pelo desconhecimento da existência delas.

Em síntese, novos estudos sobre a temática poderão avançar em aspectos poucos desenvolvidos pelo conjunto dos trabalhos analisados, a saber: estabelecimento de relações entre os dados da pesquisa empírica e o contexto mais amplo da educação brasileira; análise e interpretação dos dados, de modo geral os estudos limitaram-se à descrição dos dados com algumas análises; considerar para a definição do objeto de estudo, os objetivos e o método, pesquisas anteriores (teses e dissertações) sobre o tema, ou seja, partir do conhecimento produzido buscando responder às lacunas existentes e o aprofundamento de aspectos pouco desenvolvidos em pesquisas anteriores. Nesta perspectiva, as pesquisas de revisão sistemática podem trazer importantes contribuições, na medida em que oferecem dados e informações da produção acadêmica sobre uma determinada temática.

\section{Referências}

ARELARO, L. R. G. A (ex)tensão do ensino básico no Brasil: um avesso de um direito democrático. Tese (Doutorado em Educação) - Faculdade de Educação, Universidade de São Paulo, São Paulo, 1988.

AZANHA, J. M. P. Educação: alguns escritos. São Paulo: Nacional, 1987.

AZEVEDO, J. C. de. Escola Cidadã: desafios, diálogos e travessias. Petrópolis, RJ: Vozes, 2000.

BARRETO, E. S. de Sá; MITRULIS, E. Os ciclos escolares: elementos de uma trajetória. Cadernos de Pesquisa, Rio de Janeiro, n. 108, p. 27-48, nov. 1999. 
BARRETO, E. S. de Sá et al. Avaliação na educação básica nos anos 90 segundo os periódicos acadêmicos. Cadernos de Pesquisa, Rio de Janeiro, n. 114, p. 4988, novembro, 2001.

BARDIN, L. Análise de conteúdo. 3. ed. Lisboa, Portugal: Edições 70, 2004.

BELO HORIZONTE (Minas Gerais). Secretaria Municipal de Educação. Escola Plural: proposta político-pedagógica. Brasília: MEC/SEF, 1994.

BRASIL. Lei n. 5.692, de 11 de agosto de 1971. Fixa diretrizes e bases para o Ensino de $1^{\circ}$ e $2^{\circ}$ graus, e dá outras providências. Diário Oficial da União, Brasília, DF, 12 ago. 1971. Disponível em: <http://www.planalto.gov.br/ ccivil_03/leis/L5692.htm>. Acesso em: 23 dez. 2012.

. Lei n. 9.394 de 20 de dezembro de 1996. Estabelece as diretrizes e bases da Educação Nacional. Diário Oficial da União, Brasília, DF, 23 dez. 1996. Disponível em: < http://portal.mec.gov.br/seesp/arquivos/pdf/lei9394_ ldbn1.pdf >. Acesso em: 23 dez. 2012.

CABRERA, R. C. Docência e desespero: avaliação da aprendizagem na escola ciclada. Brasília: Liber Livro Editora, 2006.

CAMPOS, A. Escola Ciclada: concepções, trajetórias e experiências dos ciclos de formação nas escolas cuiadanas. Cuiabá: KCM, 2008.

CONTIERO, A. S. O regime de progressão continuada no Estado de São Paulo: indicadores e perspectivas para novas pesquisas. 2009. Dissertação (Mestrado)-Programa de Pós-Graduação em Educação, Universidade Metodista de Piracicaba, Piracicaba, 2009.

DAVIES, P. Revisões sistemáticas e a Campbell Collaboration. In: THOMAS, G.; PRING, R. Educação baseada em evidências: a utilização dos achados científicos para a qualificação da prática pedagógica. Porto Alegre: Artmed, 2007.

ESTEBAN, M. T. O que sabe quem erra? reflexões sobre avaliação e fracasso escolar. Rio de Janeiro: DP\&A, 2002. 
FREITAS, L. C de. Ciclos, seriação e avaliação: confronto de lógicas. São Paulo: Moderna, 2003a.

. (Org). Questões de avaliação educacional. Campinas, SP: Komedi, $2003 b$.

GOUGH, D. Síntese sistemática de pesquisa. In: THOMAS, G.; PRING, R. Educação baseada em evidências: a utilização dos achados científicos para a qualificação da prática pedagógica. Porto Alegre: Artmed, 2007.

JACOMINI, M. A. Uma década de organização do ensino em ciclos na rede municipal de São Paulo: um olhar dos educadores. 2002. Dissertação (Mestrado)-Programa de Pós-Graduação em Educação, Faculdade de Educação, Universidade de São Paulo, São Paulo, 2002.

. Educar sem reprovar. São Paulo: Cortez, 2010.

KNOBLAUCH, A. Ciclos de aprendizagem e avaliação de alunos: o que a prática escolar nos revela. Araraquara, SP: JM Editora, 2004.

LÜDKE, M; ANDRÉ, M. E. D. A. Pesquisa em educação: abordagens qualitativas. São Paulo: EPU, 1986.

LUCKESI, C. C. Avaliação da aprendizagem escolar. São Paulo: Cortez, 2000.

MAINARDES, J.; GOMES, A. C. Avaliação da aprendizagem e escola em ciclos: uma revisão de literatura (2000-2006). In: FETZNER, A. R. (Org.). Ciclos em Revista - Avaliação: desejos, vozes, diálogos e processos, Rio de Janeiro, 2008, v. 4, p. 233-250, 2008.

MAINARDES, J. A pesquisa sobre a organização da escolaridade em ciclos no Brasil (2000-2006): mapeamento e problematizações. Revista Brasileira de Educação, [S.1.], v. 14, n. 40 jan./abr. 2009.

. Organização da escolaridade em ciclos no Brasil: revisão da literatura e perspectivas para a pesquisa. Educação e Pesquisa, São Paulo, v. 32, n.1, p. 11-30, jan./abr. 2006. 
. A pesquisa sobre a política de ciclos no Brasil: panorama e desafios. Ciclos em revista, Rio de Janeiro, v. 1, p. 113-126. 2007a.

. Reinterpretando os ciclos de aprendizagem. São Paulo: Cortez, 2007b.

MANSANO FILHO, R.; OLIVEIRA, R.P. de; CAMARGO, R. B. de. Tendências da matrícula no ensino fundamental regular no Brasil. In: OLIVEIRA, C. de, et al. Municipalização do ensino no Brasil. Belo Horizonte: Autêntica, 1999.

MOREIRA, A. N. G. Melhores IDEB do Ceará 2005-2007: aprendizagem efetiva ou aprovação automática? In: FREITAS, D. N. T. de; REAL, G. C. M. (Org.). Políticas e monitoramento da qualidade do ensino fundamental: cenários municipais. Dourados, MS: Ed. UFGD, 2011.

PARO, V. H. Reprovação Escolar: renúncia à educação. São Paulo: Xamã, 2001.

PERRENOUD, P. Avaliação: da excelência à regulação das aprendizagens entre duas lógicas. Porto Alegre: Artmed, 1999.

PORTO ALEGRE (Rio Grande do Sul). Secretaria Municipal de Educação. Cadernos Pedagógicos SMED No 9, Porto Alegre, [1996].

RAVITCH, D. The death and life of the great american school system: how testing and choice are undermining education. Basic Books: New York, 2010.

SÃO PAULO. Secretaria Municipal de Educação. Regimento comum das escolas municipais de São Paulo. São Paulo, 1992.

. Conselho Estadual de Educação. Deliberação CEE n. 9/97. 1997. Disponível em: $<$ http://www.crmariocovas.sp.gov.br/pdf/diretrizes_p08200830_c.pdf>. Acesso em: 24 dez. 2012.

. Secretaria de Estado da Educação. Resolução SE n. 124, de 13 de novembro de 2001. Dispõe sobre a realização das provas de avaliação dos Ciclos I e II do Ensino Fundamental, nas escolas da rede estadual de ensino, em 2001. Disponível em: <http://siau.edunet.sp.gov.br/ItemLise/arquivos/124_2001. htm>. Acesso em: 24 dez. 2012. 
SOUSA, S. Z. L.; BARRETO, E. S. de S. Estado do conhecimento ciclos e progressão escolar (1990-2002). Relatório final. Faculdade de Educação, Universidade de São Paulo, São Paulo, 2004.

STAKE, R. E. Pesquisa qualitativa/naturalista: problemas epistemológicos. Educação e Seleção, Rio de Janeiro, n. 7, jan./jun., 1983.

STREMEL, S.; MAINARDES, J. Levantamento de teses e dissertações sobre progressão continuada - 2000 a 2010.2011. Disponível em: <http://www.uepg. br/gppepe>. Acesso em: 23 jan. 2014.

VIDAL, E. M.; VIEIRA, S. L. Gestão Educacional e resultados no IDEB: um estudo de caso em dez municípios cearenses. In: FREITAS, D. N. T. de; REAL, G. C. M (Orgs). Políticas e monitoramento da qualidade do ensino fundamental: cenários municipais. Dourados, MS: Ed. UFGD, 2011.

\section{Assessment of learning over times of continued progression: what has changed? A study of Master and Doctorate reports on the subject (2000-2010) Abstract}

This article is about learning assessment for continuous progression system, and it analyzed 22 reports for master and doctorate levels over the period of 2000-2010. It is an academic review and the following information was obtained through the entire reading of texts: bibliographic reference, text structure, methodological procedures, objectives, theoretical framework, conclusions, abstract quality and debate contributions. It has been found that the referred reports did not mention the ones previously written on the same subject and there had been no contribution for news findings. It has been concluded that future work on this topic ought to talk about those aspects which have not yet been mentioned on the analyzed researches as follows: the establishment of relations between the data of empirical research and the broader context of Brazilian education and the improvement of the data analysis and interpretation. Therefore, it is important to emphasize that the research of the academic production review may bring valuable contributions for further studies.

Keywords: Review of academic literature. Assessment. Continued progression 


\section{Evaluación del aprendizaje en tiempos de progresión continua: ¿qué ha cambiado? Un estudio de tesis y disertaciones sobre el tema (2000-2010) \\ Resumen}

En este artículo se analizan 22 tesis y disertaciones producidas durante el periodo de 2000 a 2010, sobre el sistema de evaluación escolar de progresión continua. Se trata de un trabajo de revisión académica, de una lectura minuciosa de textos y recolección de informaciones, tales como: referencia bibliográfica, estructura de trabajo, procedimientos metodológicos, objetivos, marco teórico, conclusiones, resumen y calidad de las contribuciones al debate. Se verificó que los trabajos hicieron poca referencia a las investigaciones correlativas y casi no trajeron nuevas contribuciones. Se concluyó que las futuras investigaciones académicas sobre este tema deben avanzar en aspectos poco desarrollados en los trabajos analizados como el establecimiento de relaciones entre los datos de la investigación empírica y el contexto más amplio de la educación brasileña y profundizar el análisis e interpretación de datos. Para ello, los análisis de revisión de la producción académica pueden aportar contribuciones importantes. Palabras clave: Revisión de producción académica. Evaluación. Progresión continua. 